\title{
Hydraulic resistance of thermal deaerators of thermal power stations (TPS) with jet-film contact devices
}

\author{
Ilnur N. Madyshev ${ }^{1 *}$, Oksana S. Dmitrieva ${ }^{2}$, and Andrey V. Dmitriev ${ }^{2}$ \\ ${ }^{1}$ Kazan National Research Technological University, 420016 Kazan, Russia \\ ${ }^{2}$ Kazan State Power Engineering University, 420066 Kazan, Russia
}

\begin{abstract}
One of the methods of solving the problem of improvement of heat-mass efficiency of thermal deaerators of TPSs is application of jetfilm contact devices for interaction of vapor and liquid flows. The design of these devices has been studied. Estimate calculations of hydraulic resistance have been carried out. We have obtained the equation for calculation of resistance coefficient, depending on the height of element of contact device.
\end{abstract}

\section{Introduction}

Thermal deaeration of heat transfer water agent is one of the most important activities, ensuring water-chemistry conditions for power facilities [1]. At the same time, reliability and operation efficiency of power asset depends on the efficiency of water deaeration processes. Reliability is due to the intensity of corrosion processes of steel pipelines and equipment, and the efficiency is related to the presence of non-condensable gases in the water vapor, which hinder the heat transfer during condensation [2].

A possible way of solving the problem of improvement of heat-mass efficiency of thermal deaerators of TPSs is application of jet-film contact devices for interaction of vapor and liquid flows. Currently known designs of jet bubbling, jet and film deaerators are of large dimensions and very metal-intensive. This is due to the relatively low intensity and efficiency of heat-mass transfer processes, occurring in these devices. Besides, many designs of contact devices have low throughput capacity, while operation within area of high vapor velocities leads to an intensive liquid removal and the "flooding" of deaerator column.

\section{Description of jet-film contact devices}

The aforementioned shortcomings were eliminated in the jet-film contact devices [3], developed by the authors. The contact devise (Fig. 1) consists of parallel square drain cups 1 with vertical walls, required for maintaining the liquid level inside of them. Vertical perforated baffles 2 are the supports for drain cups 1 and have slotted holes for the

* Corresponding author: ilnyr 91@mail.ru 
installation of appropriate drain cups 1 . The drain cups 1 are open from the top end, but recurved leaves 3 in the form of circular segments are executed in the bottom of cups. These segments are required for the liquid distribution over the surface of vertical perforated baffles 2 .

The proposed jet-film contact device operates as follows. The liquid, through the plurality of recurved leaves 3 , performed in the bottom of drain cups 1 , is dispersed in the form of jets to the below located vertical perforated baffles 2 . Thus, the liquid level in these drain cups 1 , is maintained by means of vertical walls of drain cups. The drain cups 1 are arranged horizontally chequerwise, forming a tray. The below tray has an offset of drain cups, forming vertical chequerwise arrangement of them. For this reason, vapor, coming to underneath the plate, acquires a zigzag nature of movement.

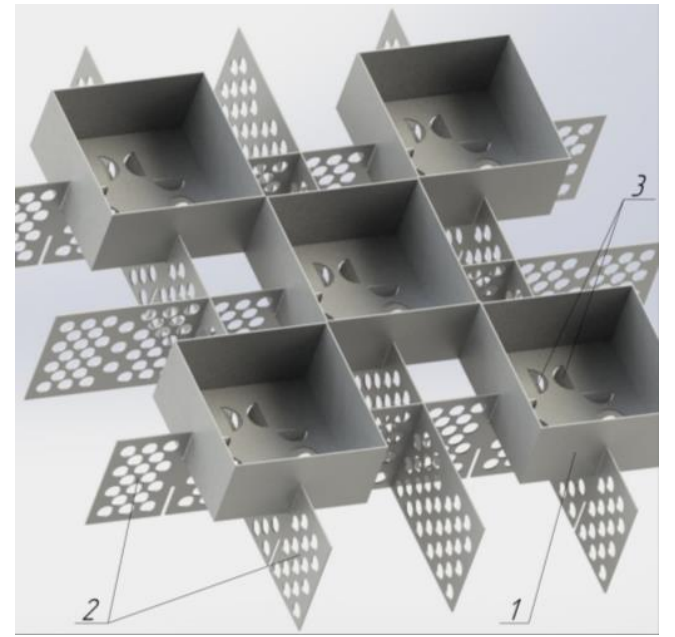

Fig. 1. Jet-film contact device: 1 - drain cup; 2 - baffles; 3 - recurved leaves.

When liquid jets move along the surface of vertical baffles 2, the liquid is distributed with formation of a stable film flow. Thus, the coming down liquid film interacts with an ascending vapor flow. After that, the formed film, colliding with liquid surface inside of drain cups 1 , collapses. Thus, there is a developed, continuously renewing surface of contact of phases, which is determined by the presence of relatively small vapor bubbles in the liquid layer and droplets, departing from the surface. The presence of holes leads to alignment of the profile of concentrations in the coming down liquid film and its more uniform distribution over the surface of baffles. Besides, metal consumption of the proposed design reduces. When distances between the drain cups, arranged at the same level, are equal to width of a drain cup, it provides stable, uniform vapor flow, which leads to reduction of hydraulic resistance of jet-film contact device. Thus, organization of original interaction between vapor and liquid allows stimulating heat-mass transfer processes both in liquid and in vapor phases at relatively simple apparatus design.

\section{Analysis of the results of numerical calculations}

The purpose of numerical studies is to determine the hydraulic resistance of proposed contact devices. For that purpose, all-gas (air) flows with a temperature of $20^{\circ} \mathrm{C}$ through the layer of contact elements, consisting of 3 stages, were computer simulated via ANSYS Fluent software application. Width of drain cup has been taken equal to $100 \mathrm{~mm}$. During numerical studies, the height of drain cup has been varied from 10 up to $30 \mathrm{~mm}$, as well as gas velocity in the cross section of apparatus - from 1 up to $10 \mathrm{~m} / \mathrm{s}$. As the main model, we 
chose a modification of the two-parametric turbulence model k- $\omega$ SST-model, showing satisfactory agreement with experimental data, obtained in earlier studies [4, 5].

The resistance of dry layer of contact elements can be determined by Darcy-Welsbach modified equation:

$$
\Delta p=\xi \frac{H}{b} \frac{\rho_{G} W_{G}^{2}}{2},
$$

where $\xi$ - resistance coefficient; $H$ - height of contact elements layer, $\mathrm{m} ; b$ - width of drain cup, $\mathrm{m} ; \rho_{G}-$ gas density, $\mathrm{kg} / \mathrm{m}^{3} ; W_{G}-$ gas velocity in the cross section of apparatus, $\mathrm{m} / \mathrm{s}$.

Height of contact stage is related to height of drain cup by the following ratio:

$$
h_{c m}=b+h_{1},
$$

где $h_{1}$ - высота сливного стакана, м.

Fig. 2 shows the dependence of hydraulic resistance of jet-film contact devices from gas flow velocity in the cross section of apparatus. The diagram shows that increasing the height of drain cup from 10 up to $30 \mathrm{~mm}$ leads to decrease of hydraulic resistance by $1.43-$ 1.46 times.

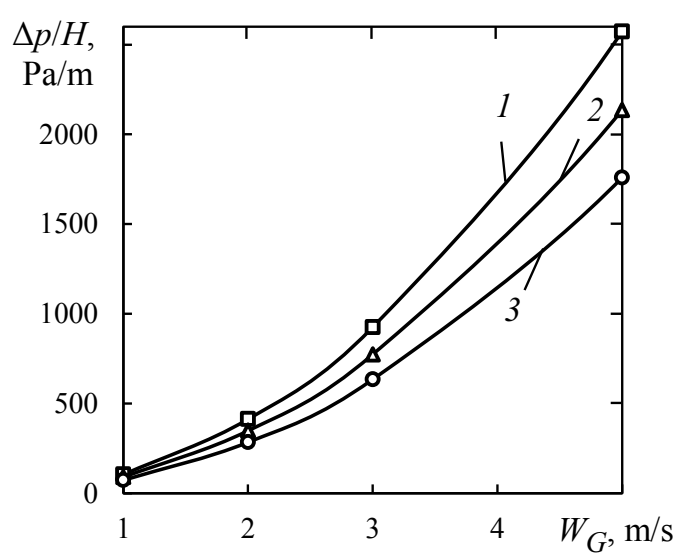

Fig. 2. Specific hydraulic resistance of jet-film contact devices, depending on gas velocity in the cross section of apparatus at different height of drain cup $h_{1}, \mathrm{~mm}: 1-10 ; 2-20 ; 3-30$.

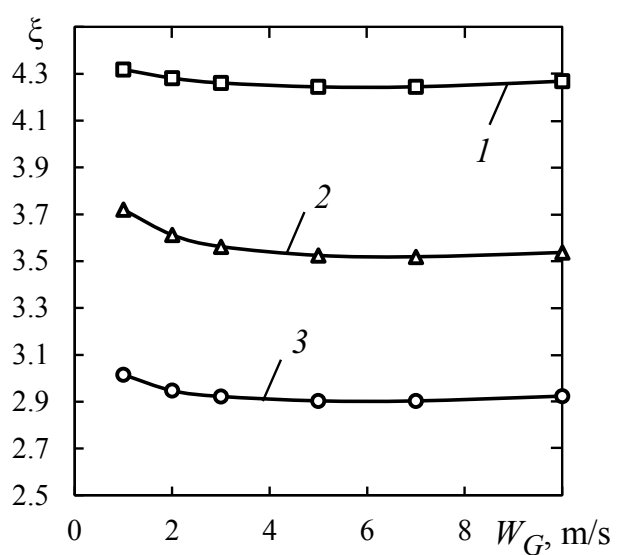

Fig. 3. Dependence of resistance coefficient of jet-film contact devices from gas velocity in the cross section of apparatus at different height of drain cup $h_{1}$, mm: $1-10 ; 2-20 ; 3-$ 30 .

Analyzing the data, shown in Fig. 3, it can be concluded that resistance coefficient is practically independent from gas velocity in the cross section of apparatus, as its change under the studied conditions does not exceed 5.7\%. Processing of numerical simulation results allowed us to obtain dependence of resistance coefficient from height of drain cup in the following form:

$$
\xi=-67.134 h_{1}+4.9508
$$

approximation certainty factor of which is equal to 0.9992 . 


\section{Conclusion}

On the basis of numerical calculations we can draw the following conclusion: a equation (3) calculates the resistance coefficient with accuracy sufficient for practice, and it can be used to predict the hydraulic resistance of thermal deaerators of TPS with jet-film contact devices. Thus, it can be said that application of proposed contact devices inside of deaerators of industrial TPSs is promising, as they can improve the efficiency of water thermal deaeration process at low energy costs.

The reported study was funded by RFBR, according to the research project No. 16-38-60081 mol_a_dk.

\section{References}

1. A.A. Abramovskikh, U.A. Ulyanova, S.V. Lavrinenko, A.A. Matveeva, D. Malishev, MATEC Web of Conferences, 91, 01002 (2017)

2. V.I. Sharapov, E.V. Kudryavtseva, Power Tech. and Eng., 50, 2, 204 (2016)

3. O.S. Dmitrieva, A.V. Dmitriev, L.V. Kruglov, Procedia Engineering, 150, 753 (2016)

4. O.S. Dmitrieva, I.N. Madyshev, A.V. Dmitriev, J. Eng. Phys. Thermophys., 90, 3, 651 (2017)

5. O.S. Dmitrieva, A.V. Dmitriev, I.N. Madyshev, A.N. Nikolaev, Chemical and Petroleum Engineering, 53 (1-2), 130 (2017) 